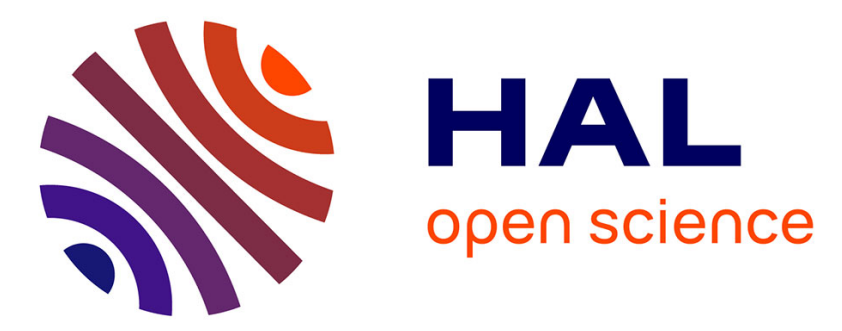

\title{
Charge separation in an acceptor-donor-acceptor triad material with a lamellar structure
}

D. Rolland, J. C. Brauer, L. Hartmann, Laure Biniek, Martin Brinkmann, N. Banerji, H. Frauenrath

\section{> To cite this version:}

D. Rolland, J. C. Brauer, L. Hartmann, Laure Biniek, Martin Brinkmann, et al.. Charge separation in an acceptor-donor-acceptor triad material with a lamellar structure. Journal of Materials Chemistry C, 2017, 5 (6), pp.1383-1393. 10.1039/C6TC03786K . hal-02340661

\section{HAL Id: hal-02340661 \\ https://hal.science/hal-02340661}

Submitted on 10 Dec 2021

HAL is a multi-disciplinary open access archive for the deposit and dissemination of scientific research documents, whether they are published or not. The documents may come from teaching and research institutions in France or abroad, or from public or private research centers.
L'archive ouverte pluridisciplinaire HAL, est destinée au dépôt et à la diffusion de documents scientifiques de niveau recherche, publiés ou non, émanant des établissements d'enseignement et de recherche français ou étrangers, des laboratoires publics ou privés. 


\title{
Journal of Materials Chemistry C
}

\section{ARTICLE}

\section{Charge Separation in an Acceptor-Donor-Acceptor Triad Material with a Lamellar Structure}

Received 00th January 20xx, Accepted 00th January 20xx

DOI: $10.1039 / \times 0 \times x 00000 x$

www.rsc.org/

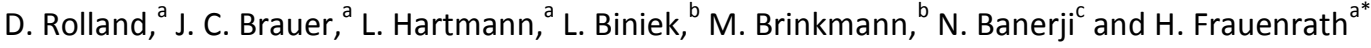

Covalently linking both electron donor and acceptor components is an efficient way to gain thermodynamic control over the formation of well-ordered heterojunction materials suitable for organic photovoltaics. In this context, we attached flexible polymer segments to the termini of a (perylene bisimide)-quaterthiophene-(perylene bisimide) triad. The microphase segregation of the resulting coil-rod-coil architecture served to reliably promote the formation of lamellar phases. The lamellae were oriented vertical relative to the substrate, and they could be laterally aligned by mechanical rubbing, as determined by small and wide angle X-ray scattering, transmission electron microscopy, electron diffraction and AFM. Transient absorption spectroscopy revealed that light absorption was followed by charge separation and that charge recombination was slower in thin films than for solution-phase samples, especially when longer side chains were used. Thus, this study is a first step towards reliable lamellar phase segregation in donor-acceptor materials on the route towards improved materials for organic photovoltaics.
\end{abstract}

\section{Introduction}

Research on photovoltaic devices is one of the corner stones of solving the problems associated with the world's growing energy demand. ${ }^{1,2}$ In this context, the use of organic materials promises a low cost production of large area, flexible, and light-weight devices. In organic photovoltaic materials, charge generation at the interface between an electron donor and an acceptor component as well as charge extraction towards the electrodes are the two crucial steps that determine device performance. ${ }^{3-5}$ Therefore, both a large interface and continuous charge percolation pathways are essential for an overall efficient energy conversion. The active layer microstructure is one of the most important parameters determining device performance. ${ }^{6}$ To this end, blending the donor and the acceptor components such that they form an interpenetrating network called "bulk heterojunction" (BHJ) has been the most successful strategy to date. ${ }^{7-9}$ In $\mathrm{BHJ}$ devices based on an electron donor polymer and a fullerene acceptor, for instance, the formation of a three-phase microstructure, including an intimately mixed phase of the two components, plays a major role for their superior efficiency. ${ }^{10-13}$ However,

\footnotetext{
a. Laboratory of Macromolecular and Organic Materials, Institute of Materials, Ecole Polytechnique Fédérale de Lausanne. EPFL-STI-IMX-LMOM, MXG 135, Station 12, 1015 Lausanne, Switzerland. E-mail: holger.frauenrath@epfl.ch

${ }^{b}$. Institut Charles Sadron, CNRS-Université de Strasbourg, 23 rue du loess, 67034 Strasbourg, France.

Department of Chemistry, University of Fribourg, Chemin du Musée 9, CH-1700 Fribourg, Switzerland.

Electronic Supplementary Information (ESI) available: Absorption spectra of all TA samples and TA spectra of the individual chromophores. See DOI: $10.1039 / \times 0 \times x 00000 x$
}

the exact microstructure of BHJs is difficult to control, and they still contain large domains that result in increased exciton recombination as well as isolated domains that trap charges. Moreover, their kinetically controlled formation results in metastable morphologies that slowly undergo macrophase segregation, resulting in significantly reduced device performance over time. ${ }^{9,14}$

Covalently connecting the donor and acceptor components has been explored as an approach to address these issues. ${ }^{15-17}$ For example, brush copolymers of acceptor moieties grafted to an electron-rich polymer backbone as the donor component have been referred to as "double-cables" that transport electrons through the pendant groups and holes through the polymer backbone. Similarly, dyads or triads of small molecule donors and acceptors have been designed with the purpose of maximizing the donor/acceptor interface. The intimate mixing of the donor and acceptor moieties in such "molecular heterojunctions" is supposedly related to the mixed phase observed in polymer:fullerene BHJs. However, typical power conversion efficiencies of devices using such materials were often lower than those of devices prepared from the corresponding blends, ${ }^{16-18}$ presumably due to better charge extraction and limited recombination helped by larger domains of the pure components in the blends. One may conclude that covalently linking the donor and acceptor components should be complemented with the formation of nanostructures with at least one extended dimension in socalled "ordered heterojunctions". In this context, various groups prepared donor-acceptor co-oligomers e.g. dyads (AD) or triads (ADA and DAD). Hashimoto et al. prepared a fullerene-substituted oligothiophene that formed lamellar phases in thin films. ${ }^{19}$ Geng et al. as well as Méry et al. 


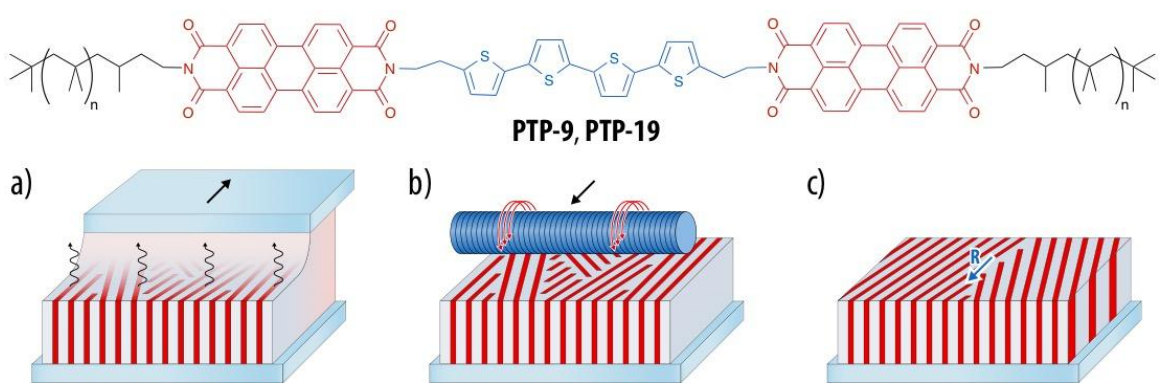

Figure 1. Molecular structure of the polymer-substituted donor-acceptor-donor triads and preparation of thin films. $a$ ) Thin films of PTP-9 or PTP-19 ( $n=9$ or 19 , respectively) were prepared by doctor blading and exhibited a lamellar phase with an "edge-on" orientation of the lamellae relative to the substrate and different lateral orientations. b) Mechanical rubbing and annealing resulted in c) a macroscopic alignment of the lamellar phase parallel to the rubbing direction.

prepared liquid-crystalline dyads comprising fluorene and thiophene subunits in the donor block and a perylene acceptor block that self-assembled into lamellar phases with separated donor and acceptor domains. ${ }^{20-22}$ Tuning the band gap of the donor part and adding a flexible alkyl spacer between the donor and acceptor to accommodate packing constraints resulted in a power conversion efficiency of $2.7 \%,{ }^{23}$ which represents one of the best values reported for a singlecomponent organic solar cell, but is still low compared to BHJs. This problem has mostly been attributed to the lack of longrange order; as the lamellar thickness is typically on the order of only a few nanometers, an increasing number of defects will favor charge recombination. Moreover, charge transport may be impeded by an inappropriate molecular orientation within the lamellae.

Here, we show that terminally attaching soft polymer segments to an acceptor-donor-acceptor triad can help to obtain thin films comprising well-ordered lamellar nanostructures (Figure 1). This "coil-triad-coil" architecture was deliberately chosen because microphase segregation between the coil segments and the rod-like triad core was expected to strongly favor morphologies with low-curvature interfaces, such as lamellar phases. The resulting confinement of the triad core should consequently promote a packing of the acceptor and donor segments into separate sublayers. We chose to investigate the triad (perylene bisimide)quaterthiophene-(perylene bisimide) substituted with two poly(isobutylene) (PIB) segments of different lengths (numberaverage degrees of polymerization $P_{n}=9$ and 19) that will be named PTP-9 and PTP-19, respectively. The triads were shown to form lamellar phases, with an "edge-on" orientation of the layers relative to the substrate. Rubbing and annealing served to achieve a macroscopic alignment of the lamellar phases. In this context, the longer polymer segments of PTP-19 helped to prevent the lamellae to attain a face-on orientation that was observed in the case of PTP-9 after rubbing and annealing. Femtosecond-resolved transient absorption (TA) studies confirmed that light absorption was followed by charge separation and that the lifetime of the charges was increased in thin films in comparison to solution-phase samples. In this way, our study represents a first step towards reliable lamellar phase segregation in donor-acceptor materials on the route towards improved materials for organic photovoltaics.

\section{Experimental}

\section{Instrumentation and Methods}

Mass Spectrometry. Mass Spectra were recorded at the Mass Spectrometry Service of EPFL on either a Waters Q-TOF Ultima for ESI-TOF, a Shimadzu Biotech AXIMA Performance for MALDI-TOF, or on a Thermo Scientific LTQ FT-ICR MS for APPI.

NMR Spectroscopy. ${ }^{1} \mathrm{H}$ and ${ }^{13} \mathrm{C}$ NMR spectroscopy was carried out on Bruker Avance 400 or 600 spectrometers operating at frequencies of $400.13 \mathrm{MHz}$ or $600.13 \mathrm{MHz}$ for ${ }^{1} \mathrm{H}$ nuclei, and $100.62 \mathrm{MHz}$ or $150.91 \mathrm{MHz}$ for ${ }^{13} \mathrm{C}$ nuclei, respectively. Deuterated solvents were purchased from Cambridge Isotope Laboratories, Inc. The spectra were calibrated to the respective residual proton peaks of the deuterated solvents ( ${ }^{1} \mathrm{H}$ NMR: $7.26 \mathrm{ppm} \mathrm{CDCl}_{3}, 2.50 \mathrm{ppm} \mathrm{DMSO}-\mathrm{d}_{6}$, and $6.00 \mathrm{ppm}$ for TCE- $\mathrm{d}_{2} ;{ }^{13} \mathrm{C}$ NMR: $77.00 \mathrm{ppm}$ for $\mathrm{CDCl}_{3}$, and $40.45 \mathrm{ppm}$ for DMSO- $d_{6}$ ). Data are reported as follows: $s=$ singlet, $\mathrm{d}$ = doublet, $\mathrm{t}=$ triplet, $\mathrm{q}=$ quartet, $\mathrm{m}=$ multiplet). Coupling constants $J$ are reported in $\mathrm{Hz}$. The coupling patterns and coupling constants were evaluated with Mestrenova NMR data processing.

SAXS and WAXS. Measurements were performed in collaboration with Dr. Sandor Balog at the Adolphe Merklé Institute, Fribourg with a NanoMax-IQ camera (Rigaku Innovative Technologies, Auburn Hills, USA). The samples were kept in vacuum at room temperature during the measurements. The scattering data were presented as a function of the scattering vector modulus $q=4 \pi / \lambda \sin (\vartheta / 2)$, where $\vartheta$ is the scattering angle and $\lambda$ is the photon wavelength.

Thin Film Rubbing, Transmission Electron Microscopy, and Electron Diffraction. Thin film samples were prepared by doctor-blading from sample solutions in orthodichlorobenzene $(c=5 \mathrm{mg} / \mathrm{mL})$ on a clean glass substrate maintained at $170^{\circ} \mathrm{C}$. The thin films were subsequently rubbed with a microfiber cloth in an inert atmosphere in a glove box (Plas labs Inc.). The rubbing apparatus consisted of a rotating cylinder ( $4 \mathrm{~cm}$ diameter) covered by a microfiber cloth. The rubbing was performed by applying the rotating cylinder with a 2 bar pressure on the translating sample holder $(1 \mathrm{~cm} / \mathrm{s})$ such that it took accordingly $5 \mathrm{~s}$ to align a $5 \mathrm{~cm}$ long film. The sample holder was heated at different temperatures in the range of $25-200^{\circ} \mathrm{C}$ during the rubbing process and the 
temperature was allowed to equilibrate for 1-2 $\min$ before rubbing. One rubbing cycle corresponded to a rubbing length (i.e. the length of the rubbing tissue applied at a given point of the sample) of $50 \mathrm{~cm}$. The films were finally annealed in a Linkam LTS420 hotplate under nitrogen atmosphere at $300^{\circ} \mathrm{C}$ for $5 \mathrm{~min}$ and cooled to room temperature at a rate of $10^{\circ} \mathrm{C} / \mathrm{min}$. Areas for TEM analysis were identified by optical microscopy (Leica DMR-X microscope). The thin film samples for TEM imaging were coated with a thin amorphous carbon film and removed from the glass substrate by floating on a diluted aqueous HF solution (10 wt \%) and subsequent recovery on TEM copper grids. TEM imaging was performed in bright field, high resolution and diffraction modes using a CM12 Philips microscope equipped with a MVIII (Soft Imaging System) charge coupled device camera.

Atomic Force Microscopy. Thin films of the triads PTP-9 and PTP-19 were analyzed in tapping mode using a Nanoscope IIla (Veeco Instruments Inc., Santa Barbara, USA) instrument at room temperature in air. Cantilevers with a resonance frequency on average of $f_{0}=325 \mathrm{kHz}$ and $k=40 \mathrm{~N} / \mathrm{m}$ were used. Scan rates between 0.5 and $2 \mathrm{~Hz}$ were applied, the image resolution was $512 \times 512$ pixels.

Transient Absorption Spectroscopy. Transient absorption (TA) spectra were recorded using femtosecond pulsed laser pumpprobe spectroscopy. The sample solutions were placed into a $1 \mathrm{~mm}$ cell and constantly bubbled with argon gas to provide stirring and prevent degradation by oxygen. For the thin film measurements, the samples were mounted in a custom-built sample chamber filled with argon to avoid sample degradation. The probe beam consisted of a white light continuum (350-750 nm), generated by passing a part of the $780 \mathrm{~nm}$ amplified $1 \mathrm{kHz}$ Ti:sapphire output (Clark-MXR, CPA2001) through a $5 \mathrm{~mm} \mathrm{CaF} 2$ plate. The remaining intensity of the fundamental beam was removed by a $750 \mathrm{~nm}$ low-pass filter. Excitation pulses at $390 \mathrm{~nm}$ were generated by frequency doubling of the fundamental of the laser. Excitation pulses at $540 \mathrm{~nm}$ were generated in a custom-built NOPA. The probe intensity was always less than the pump intensity, and the probe spot size was chosen to be much smaller than the pump spot size to allow for a homogeneous excitation over the probed area. The pump pulses were delayed with respect to the probe pulses using a computerized translation stage. The probe pulses were split before the sample by means of a beamsplitter into a signal (transmitted through the sample) and a reference beam. The probe signal and reference beams were detected separately using a pair of $163 \mathrm{~mm}$ spectrographs (Princeton instruments, SpectraPro 2500i) equipped with $512 \times 58$ pixel back-thinned CCDs (Hamamatsu S07030-0906) and assembled by Entwicklungsbüro Stresing, Berlin. The pump beam was chopped as half the amplifier frequency to improve the sensitivity of the set-up. The transmitted intensity of the probe beam was recorded shot by shot and corrected for laser intensity fluctuations using the reference beam. The transient spectra were averaged at each delay until the desired signal-to-noise ratio was achieved (3000 times). To avoid polarization effects, the relative polarization of the probe and pump pulses was set to the magic angle. All spectra were corrected for the chirp of the white-light probe.

\section{Synthetic Procedures}

N-poly(isobutene)-yl perylene-9,10-di(propylcarboxylate)-3,4dicarboximide 3a. A slurry of perylene-3,4:9,10-tetracarboxylic dianhydride $1(13.0 \mathrm{~g}, 33.1 \mathrm{mmol}), 1$-propanol $(20 \mathrm{~mL}$, $265 \mathrm{mmol})$, and DBU $(20 \mathrm{~mL}, 133 \mathrm{mmol})$ in dry DMF $(130 \mathrm{~mL})$ was stirred for $16 \mathrm{~h}$ at room temperature in an inert atmosphere. The slurry became a clear solution after $1 \mathrm{~h}$. Dry THF $(80 \mathrm{~mL})$, and then a solution of PIB-NH 2 2a $(20 \mathrm{~g}$, $16.6 \mathrm{mmol}$ ) in dry THF $(70 \mathrm{~mL})$ were added slowly to the reaction mixture. The solution was stirred vigorously for $3 \mathrm{~d}$, treated with 1-bromopropane ( $24 \mathrm{~mL}, 265 \mathrm{mmol})$, stirred for another $16 \mathrm{~h}$, and finally poured into a $1 \mathrm{M}$ aqueous $\mathrm{HCl}$ solution. The slurry was extracted three times with DCM. The combined organic phases were washed with a $1 \mathrm{M}$ aqueous $\mathrm{HCl}$ solution, two times with a saturated aqueous $\mathrm{NaCl}$ solution, and finally dried over $\mathrm{Mg}_{2} \mathrm{SO}_{4}$. The solvent was removed in vacuo, and the residue (about $38 \mathrm{~g}$ ) was purified by column chromatography (5 $\left.\mathrm{L} \mathrm{SiO}_{2}, \mathrm{DCM}\right)$ to afford pure $3 \mathrm{a}$ as a red sticky solid (12.7 g, 45\%). ${ }^{1} \mathrm{H}$ NMR $\left(400.13 \mathrm{MHz} \mathrm{CDCl}_{3}\right): \delta=$ 0.65-1.80 (m, 132H, aliphatic $H), 1.85$ (sex, $2 \mathrm{H}$, $\left.\mathrm{COOCH}_{2} \mathrm{CH}_{2} \mathrm{CH}_{3}\right)$ 4.13-4.26 (m, 2H, CH $\left.2-\mathrm{N}\right), 4.32(\mathrm{t}, 4 \mathrm{H}$, $\left.\mathrm{COOCH}_{2}\right), 8.06(\mathrm{~m}, 2 \mathrm{H}, \mathrm{ArH}), 8.35(\mathrm{~m}, 4 \mathrm{H}, \operatorname{Ar} H), 8.53(\mathrm{~m}, 2 \mathrm{H}$, $\mathrm{ArH})$.

N-poly(isobutene)-yl perylene-9,10-di(propylcarboxylate)-3,4dicarboximide 3b. A slurry of perylene-3,4:9,10-tetracarboxylic dianhydride $1(0.55 \mathrm{~g}, 1.40 \mathrm{mmol}), 1$-propanol $(0.84 \mathrm{~mL}$, $11.2 \mathrm{mmol})$, and DBU $(0.84 \mathrm{~mL}, 5.6 \mathrm{mmol})$ in dry DMF $(8 \mathrm{~mL})$ was stirred for $16 \mathrm{~h}$ at room temperature in an inert atmosphere. The slurry became a clear solution after $1 \mathrm{~h}$. Dry THF $(6 \mathrm{~mL})$, and then a solution of PIB- $\mathrm{NH}_{2} \mathbf{2 b}(11.0 \mathrm{~g}$, $9.13 \mathrm{mmol}$ ) in dry THF $(5 \mathrm{~mL})$ were added slowly to the reaction mixture. The solution was stirred vigorously for $3 \mathrm{~d}$, treated with 1-bromopropane $(1.02 \mathrm{~mL}, 11.2 \mathrm{mmol})$, stirred for another $16 \mathrm{~h}$, and finally poured into a $1 \mathrm{M}$ aqueous $\mathrm{HCl}$ solution. The slurry was extracted three times with DCM. The combined organic phases were washed with a1M aqueous $\mathrm{HCl}$ solution, two times with a saturated aqueous $\mathrm{NaCl}$ solution, and finally dried over $\mathrm{Mg}_{2} \mathrm{SO}_{4}$. The solvent was removed in vacuo, and the residue (about $1.21 \mathrm{~g}$ ) was purified by column chromatography (150 $\mathrm{mL} \mathrm{SiO}, \mathrm{DCM}$ ) to afford pure $\mathbf{3 b}$ as a red sticky solid (0.43 g, 60\%). ${ }^{1} \mathrm{H}$ NMR $\left(400.13 \mathrm{MHz}, \mathrm{CDCl}_{3}\right): \delta=$ 0.65-1.80 (m, 191H, aliphatic $H), 1.85$ (sex, 4H, $\left.\mathrm{COOCH}_{2} \mathrm{CH}_{2} \mathrm{CH}_{3}\right)$ 4.13-4.26 (m, 2H, CH $\left.2-\mathrm{N}\right), 4.32(\mathrm{t}, 4 \mathrm{H}$, $\left.\mathrm{COOCH}_{2}\right), 8.06(\mathrm{~m}, 2 \mathrm{H}, \mathrm{ArH}), 8.34(\mathrm{~m}, 4 \mathrm{H}, \operatorname{ArH}), 8.53(\mathrm{~m}, 2 \mathrm{H}$, $\mathrm{ArH})$.

$\mathrm{N}$-poly(isobutene)-yl perylene-9,10-di(carboxylic anhydride)3,4-dicarboximide 4a. N-poly(isobutene)-yl perylene-9,10di(propylcarboxylate)-3,4-dicarboximide 3 (10.14 g, $8.20 \mathrm{mmol}$ ) and $p$-toluenesolfonic acid monohydrate $(15.6 \mathrm{~g}$, $82.0 \mathrm{mmol})$ were dissolved in toluene $(150 \mathrm{~mL})$, and the resulting solution was stirred for $16 \mathrm{~h}$ at $95^{\circ} \mathrm{C}$. After cooling to room temperature, the reaction mixture was poured into $\mathrm{MeOH}(1.5 \mathrm{~L})$, and the resulting slurry was stirred for $2 \mathrm{~h}$. The red precipitate was filtered off, washed with $\mathrm{MeOH}$, taken up 
in THF $(200 \mathrm{~mL})$, and reprecipitated into $\mathrm{MeOH}(2 \mathrm{~L})$ to afford pure $4 \mathrm{a}$ as a red sticky solid $(8.77 \mathrm{~g}, 94 \%) .{ }^{1} \mathrm{H}$ NMR $\left(400.13 \mathrm{MHz}, \mathrm{CDCl}_{3}, 120^{\circ} \mathrm{C}\right): \delta=0.65-1.85(\mathrm{~m}, 123 \mathrm{H}$, aliphatic H), 4.17-4.29 (m, 2H, CH $-\mathrm{N}), 8.58-8.72(\mathrm{~m}, 8 \mathrm{H}, \mathrm{ArH})$.

$\mathrm{N}$-poly(isobutene)-yl perylene-9,10-di(carboxylic anhydride)3,4-dicarboximide 4b. N-poly(isobutene)-yl perylene-9,10di(propylcarboxylate)-3,4-dicarboximide 3 (300 mg, $178 \mu \mathrm{mol}$ ) and $p$-toluenesolfonic acid monohydrate $(169 \mathrm{mg}, 890 \mu \mathrm{mol})$ were dissolved in toluene $(15 \mathrm{~mL})$, and the resulting solution was stirred for $16 \mathrm{~h}$ at $95^{\circ} \mathrm{C}$. After cooling to room temperature, the reaction mixture was diluted in DCM, washed with water, and dried. The red solid was taken up in THF and reprecipitated into $\mathrm{MeOH}$ to afford pure $\mathbf{4 b}$ as a red sticky solid (277 mg, 98\%). ${ }^{1} \mathrm{H}$ NMR $\left(400.13 \mathrm{MHz}, \mathrm{CDCl}_{3}\right.$, $\left.120^{\circ} \mathrm{C}\right): \delta=0.65-1.85(\mathrm{~m}, 231 \mathrm{H}$, aliphatic $H), 4.17-4.29(\mathrm{~m}, 2 \mathrm{H}$, $\left.\mathrm{CH}_{2}-\mathrm{N}\right), 8.58-8.72(\mathrm{~m}, 8 \mathrm{H}, \mathrm{ArH})$.

\section{PIB $_{9}-$ PBI-T $_{4}$-PBI-PIB 9 PTP-9.}

5-5"')-Bis(2-amino-ethyl)$2,2^{\prime}: 5^{\prime}, 2^{\prime \prime}: 5^{\prime \prime}, 2^{\prime \prime \prime}$-quaterthiophene dihydrochloride (150 mg, $360 \mu \mathrm{mol})$, perylene-9,10-dicarboxylic anhydride-3,4-dicarboximide-N-(polyisobutyl) 4a (858 mg, $756 \mu \mathrm{mol})$, and $\mathrm{Zn}(\mathrm{OAc})_{2}$ $(132 \mathrm{mg}, 720 \mu \mathrm{mol})$ were dissolved in quinoline $(100 \mathrm{~mL})$. The resulting solution was stirred for $16 \mathrm{~h}$ at $175^{\circ} \mathrm{C}$. The reaction mixture was subsequently cooled to room temperature and then poured into $\mathrm{MeOH}(800 \mathrm{~mL})$. After stirring for $4 \mathrm{~h}$, the dark red precipitate was filtered off, redissolved in THF $(50 \mathrm{~mL})$, and reprecipitated into $\mathrm{MeOH}(500 \mathrm{~mL})$. The obtained residue was then redissolved in DCM containing $\mathrm{SiO}_{2}(100 \mathrm{~mL})$, and the slurry was evaporated to obtain the crude product dry-loaded on $\mathrm{SiO}_{2}$ for the subsequent column chromatography $(200 \mathrm{~mL} \mathrm{SiO}, \mathrm{DCM} / \mathrm{MeOH} 10: 1$, then pure THF). A final precipitation from THF to $\mathrm{MeOH}$ afforded pure PTP-9 as a red sticky solid (54 mg, 42\%). ${ }^{1} \mathrm{H}$ NMR $(400.13 \mathrm{MHz}$, TCE- $\left.\mathrm{d}_{2}, 120^{\circ} \mathrm{C}\right): \delta=0.80-2.00(\mathrm{~m}, 236 \mathrm{H}$, aliphatic $H), 3.35-3.42$ $\left(\mathrm{m}, 4 \mathrm{H}, \mathrm{CH}_{2}-\mathrm{N}\right), 4.25-4.38\left(\mathrm{~m}, 4 \mathrm{H}\right.$, quaterthiophene- $\left.\mathrm{CH}_{2} \mathrm{CH}_{2}-\mathrm{N}\right)$, 4.56-4.65 (m, 4H, quaterthiophene- $\left.\mathrm{CH}_{2} \mathrm{CH}_{2}-\mathrm{N}\right), 8.65-8.80(\mathrm{~m}$, $16 \mathrm{H}$, perylene $\mathrm{ArH}$ ). HRMS (MALDI): calcd for $\mathrm{C}_{158} \mathrm{H}_{214} \mathrm{~N}_{4} \mathrm{O}_{8} \mathrm{~S}_{4}{ }^{+}$ $\left([\mathrm{M}+\mathrm{Na}]^{+}\right)$: 2447.5270; found: 2449.819 .

PIB $_{19}-$ PBI-T $_{4}-$ PBI-PIB $_{19} \quad$ PTP-19. 5-5'"'-Bis(2-amino-ethyl)$2,2^{\prime}: 5^{\prime}, 2^{\prime \prime}: 5^{\prime \prime}, 2^{\prime \prime \prime}$-quaterthiophene dihydrochloride (15 mg, $36 \mu \mathrm{mol})$, perylene-9,10-dicarboxylic anhydride-3,4-dicarbox- imide- $\mathrm{N}$-(polyisobutyl) 4b (120 mg, $76 \mu \mathrm{mol})$, and $\mathrm{Zn}(\mathrm{OAc})_{2}$ (13 $\mathrm{mg}, 72 \mu \mathrm{mol}$ ) were dissolved in quinoline $(20 \mathrm{~mL}$ ). The resulting solution was stirred for $16 \mathrm{~h}$ at $175^{\circ} \mathrm{C}$. The reaction mixture was subsequently cooled to room temperature and then poured into $\mathrm{MeOH}(150 \mathrm{~mL})$. After stirring for $4 \mathrm{~h}$, the dark red precipitate was filtered off, redissolved in THF $(20 \mathrm{~mL})$, and reprecipitated into $\mathrm{MeOH}(150 \mathrm{~mL})$. The obtained residue was then redissolved in THF containing $\mathrm{SiO}_{2}(10 \mathrm{~mL})$, and the slurry was evaporated to obtain the crude product dry-loaded on $\mathrm{SiO}_{2}$ for the subsequent column chromatography (50 $\mathrm{mL} \mathrm{SiO}, \mathrm{DCM} / \mathrm{MeOH} 10: 1$, then pure THF). A final precipitation from THF to $\mathrm{MeOH}$ afforded pure PTP-19 as a red sticky solid (54 mg, 42\%). ${ }^{1} \mathrm{H}$ NMR $\left(400.13 \mathrm{MHz}\right.$, TCE- $\mathrm{d}_{2}$, $\left.120^{\circ} \mathrm{C}\right): \delta=0.75-1.95(\mathrm{~m}, 358 \mathrm{H}$, aliphatic $H), 3.35-3.42(\mathrm{~m}, 4 \mathrm{H}$, $\left.\mathrm{CH}_{2}-\mathrm{N}\right), 4.26-4.35\left(\mathrm{~m}, 4 \mathrm{H}\right.$, quaterthiophene- $\left.\mathrm{CH}_{2} \mathrm{CH}_{2}-\mathrm{N}\right), 4.56-$ $4.65\left(\mathrm{~m}, 4 \mathrm{H}\right.$, quaterthiophene- $\left.\mathrm{CH}_{2} \mathrm{CH}_{2}-\mathrm{N}\right), 8.65-8.80(\mathrm{~m}, 16 \mathrm{H}$, perylene $\mathrm{Ar} H$ ).

\section{Results and Discussion}

\section{Synthesis and Steady-State Spectroscopy}

The synthesis of PTP-9 and PTP-19 started from perylene bisanhydride 1 that was first coupled to the poly(isobutylene) amines $\mathrm{PIB}_{9}-\mathrm{NH}_{2} \mathbf{2 a}$ and $\mathrm{PIB}_{19}-\mathrm{NH}_{2} \mathbf{2 b}$, respectively (Scheme 1 ). Due to solubility reasons, however, a simple statistical coupling of one equivalent of the poly(isobutylene) amine to perylene bisanhydride yielded exclusively the symmetrically disubstituted product. In order to circumvent this issue, $\mathbf{1}$ was first reacted with propanol in the presence of a strong base in DMF. $^{24,25}$ The resulting partially esterified intermediate became well soluble in DMF and was then statistically reacted in situ with substoichiometric amounts of poly(isobutylene) amine $\mathbf{2} \mathbf{a}$ or $\mathbf{2} \mathbf{b}$. Addition of bromopropane finally yielded the unsymmetric perylene diesters $\mathbf{3} \mathbf{a}$ and $\mathbf{3} \mathbf{b}$, respectively. The ester functions were subsequently cleaved in acidic conditions, and the resulting perylene monoanhydrides $\mathbf{4 a}$ and $\mathbf{4} \mathbf{b}$ were coupled to $2,5^{\prime \prime \prime}$-bis(2-amino-ethyl)-5, 2':5', 2": $5^{\prime \prime}, 2^{\prime \prime \prime}$ quaterthiophene ${ }^{26}$ in quinoline at $175^{\circ} \mathrm{C}$, yielding the desired triads PTP-9 and PTP-19 (Supplementary Figure S1).

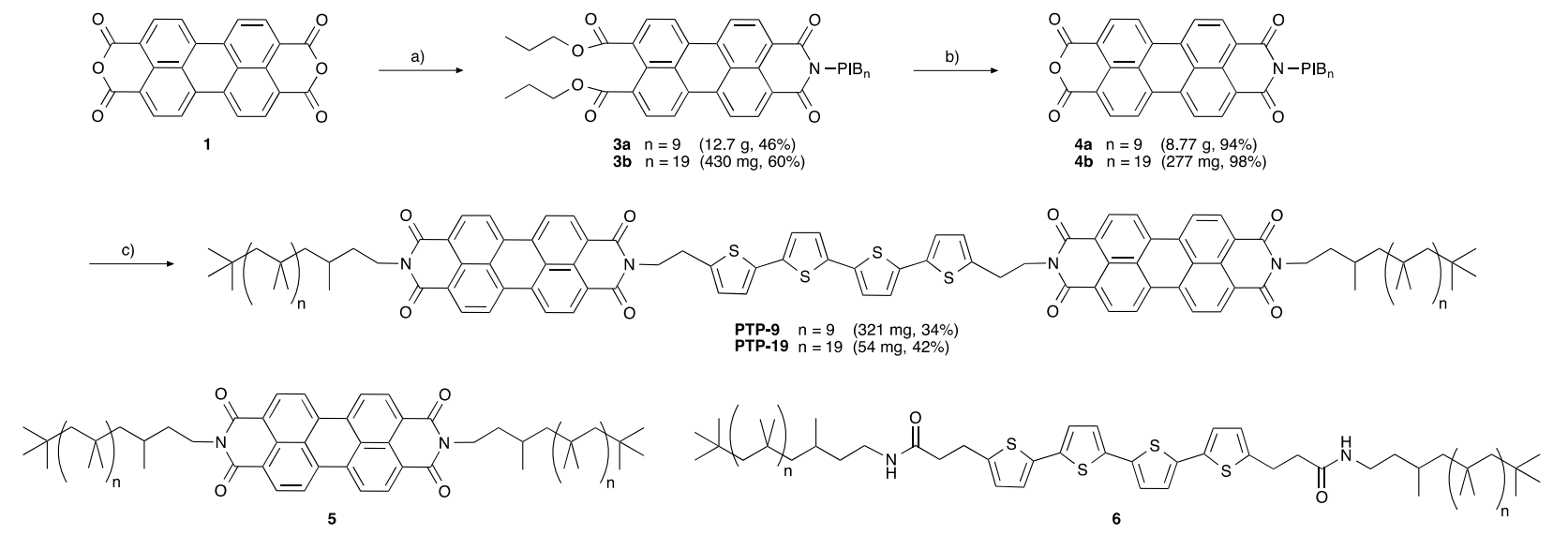

Scheme 1. Synthesis of the poly(isobutylene)-substituted triads PTP-9 and PTP-19. Reagents and conditions: a) (i) propanol, DBU, DMF, r.t., 16h; (ii) PIB-NH 2 2a or 2b,

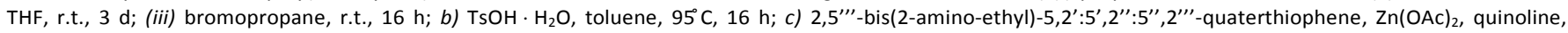
$175^{\circ} \mathrm{C}, 16 \mathrm{~h}$ 

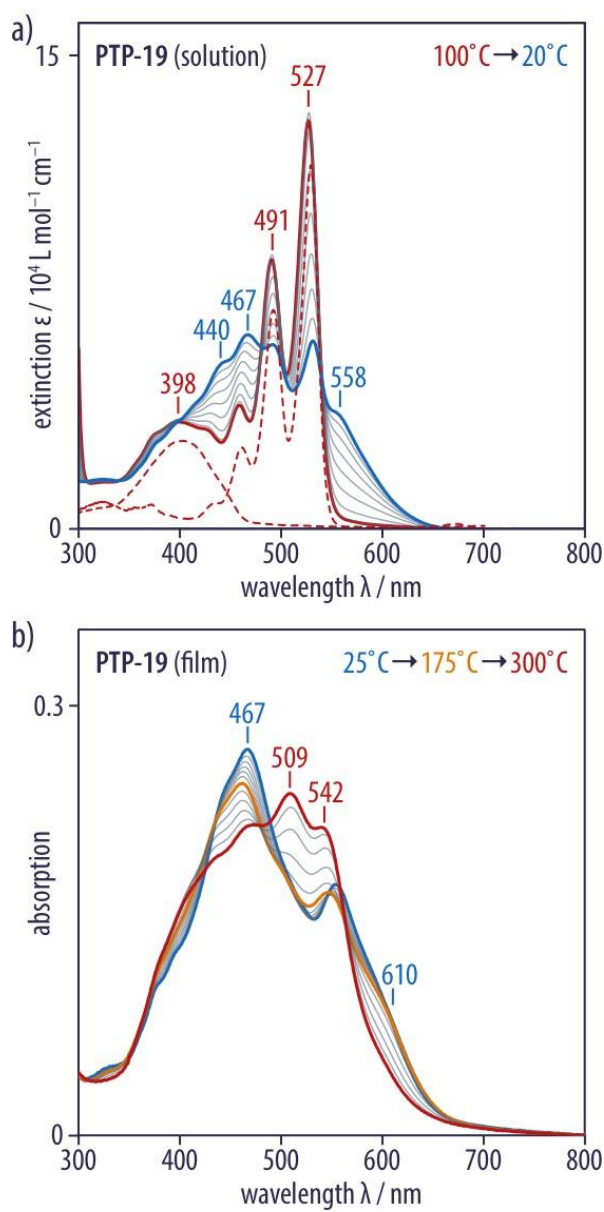

Figure 2. a) The UV/vis absorption spectrum of PTP-19 in o-dichlorobenzen ( $c=25 \mu \mathrm{mol} / \mathrm{L}$ ) at $100^{\circ} \mathrm{C}$ (red) resembled a superposition of the contributions of perylene bisimide and quaterthiophene chromophores, as seen from a comparison to the UV/vis spectra of molecularly disperse solutions of the reference compounds $\mathbf{5}$ and $\mathbf{6}$ (red, dashed). Upon cooling the solutions from $100^{\circ} \mathrm{C}$ to $20^{\circ} \mathrm{C}$ (blue; in steps of $10^{\circ} \mathrm{C}$ ), the triad formed spectroscopic aggregates, showing both $\mathrm{H}$ and $\mathrm{J}$ bands of the perylene bisimide. b) The shape of the UV/vis absorption spectra of PTP-19 in thin films remained almost unchanged upon heating from $25^{\circ} \mathrm{C}$ (blue) to $175^{\circ} \mathrm{C}$ (orange; in steps of $25^{\circ} \mathrm{C}$ ), but underwent significant changes upon further heating to $300^{\circ} \mathrm{C}$ (red; in steps of $25^{\circ} \mathrm{C}$ ).

Moreover, the poly(isobutylene)-substituted perylene bisimide 5 and the quaterthiophene 6 were prepared as reference compounds. ${ }^{26,27}$ Molecularly disperse solutions of PTP-9 and PTP-19 in $o$-dichlorobenzene $(c=25 \mu \mathrm{mol} / \mathrm{L}$ ) were obtained at $100^{\circ} \mathrm{C}$. The steady-state UV/vis absorption spectra of these solutions at $100^{\circ} \mathrm{C}$ (Figure 2a) resembled a superposition of the absorption spectra of perylene bisimide $\mathbf{5}$ and quaterthiophene $\mathbf{6}$, confirming that no significant electronic coupling occurred between both chromophores. While the solutions remained optically clear upon cooling, both blueshifted $\mathrm{H}$-bands and red-shifted J-bands appeared in the absorption spectra, indicating that the triads started to form spectroscopic aggregates. The $\mathrm{H}$-bands of the perylene bisimide chromophores presumably overlapped with the quaterthiophene absorption, so that the contribution of the latter became impossible to distinguish.

Thin film samples of PTP-9 and PTP-19 were prepared on glass slides by doctor-blading from $o$-dichlorobenzene solutions ( $c=5 \mathrm{mg} / \mathrm{mL}$ ) at $180^{\circ} \mathrm{C}$. As no thermal transitions were observed in differential scanning calorimetry up to temperatures of $380^{\circ} \mathrm{C}$ except for the poly(isobutylene) glass transition at around $-60^{\circ} \mathrm{C}$, absorption spectra of the thin films were recorded over a temperature range from $25^{\circ} \mathrm{C}$ to $300^{\circ} \mathrm{C}$ (Figure 2b). The shape of the spectra persisted up to a temperature of about $175^{\circ} \mathrm{C}$, with only a small intensity decrease of the absorption at $467 \mathrm{~nm}$. Above that temperature, the bands at $467 \mathrm{~nm}$ and $610 \mathrm{~nm}$ disappeared, and new maxima at 509 as well as $542 \mathrm{~nm}$ emerged that resemble the vibronic fine structure of non-aggregated perylene chromophores. For this reason, and although no melting transition had been observed in DSC measurements, we chose to subject film samples to further treatment at temperatures above $175^{\circ} \mathrm{C}$.

\section{Alignment and Thin Film Morphology}

In order to produce macroscopically aligned samples, the thin film samples were subjected to mechanical rubbing with a rotating cylinder covered with a cloth at a substrate temperature of $200^{\circ} \mathrm{C}$ in an inert atmosphere, followed by thermal annealing at $300^{\circ} \mathrm{C}$. According to the evolution of the dichroic ratio versus rubbing temperature (Supplementary Figure S2), the best orientation was observed for a rubbing temperature close to $200^{\circ} \mathrm{C}$. After the alignment procedure, the thin films were strongly birefringent according to polarized optical microscopy, with a uniform transmission maximum across the film when the crossed polarizers were oriented at $45^{\circ}$ relative to the rubbing direction, and a total extinction across the whole sample at $0^{\circ} / 90^{\circ}$ orientation (Figure 3a). This finding was an indication for a homogeneous alignment over the length scale of the thin film sample of $1 \times 5 \mathrm{~cm}$. Moreover, polarized UV/vis absorption spectroscopy of PTP-19 and PTP-9 revealed dichroic ratios of 2.7 and 6.4 for the main absorption band at $558 \mathrm{~nm}$, respectively, with a maximum absorption when the polarizer was oriented parallel to the rubbing direction (Figure $3 \mathrm{~b}$ ). Since the transition dipole in the PBI chromophore is oriented along the molecular long axis, ${ }^{28}$ the $\mathrm{PBI}$ molecules are hence oriented with their long axis, on average, parallel to the rubbing direction $\mathbf{R}$. We confirmed the presence of lamellar nanostructures in the rubbed thin films with macroscopically aligned lamellae oriented normal to the substrate plane by a combination of small-angle X-ray scattering (SAXS), wide-angle X-ray scattering (WAXS), transmission electron microscopy (TEM), and atomic force microscopy (AFM). SAXS measurements on bulk samples of PTP-9 exhibited series of peaks with a ratio of reciprocal spacings of $q_{1}: q_{2}: q_{3}=1: 2: 3$, as is characteristic for lamellar phases (Figure 4). For PTP-19, a ratio of $q_{1}: q_{2}: q_{3}: q_{4}=1: 2: 3: 4$ was observed, with the $q_{3}$ reflection hidden in the flank of the next reflection. The main reflections corresponded to lamellar periodicities of $6.40 \mathrm{~nm}$ (PTP-9) and $7.47 \mathrm{~nm}$ (PTP-19), which are significantly smaller than the respective molecular lengths of 10 and $13 \mathrm{~nm}$, even considering that the poly(isobutylene) segments assumed their preferred $8_{3}$ helical conformation. ${ }^{29}$ 
a)

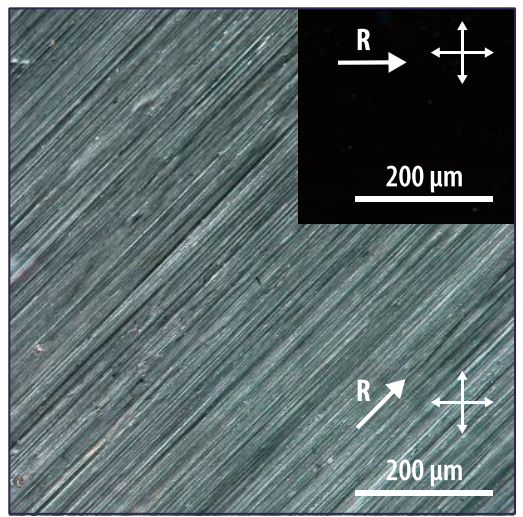

b)

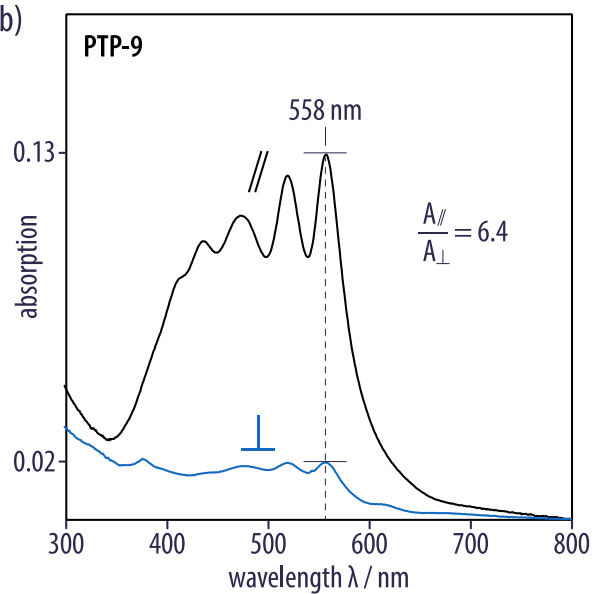

Figure 3. Aligned thin films of PTP-9 showed birefringence and dichroism. a Polarized optical micrographs showed a strong birefringence when the rubbing direction $\mathbf{R}$ (white arrow) was oriented at $45^{\circ}$ relative to the crossed polarizers, and no transmission when the rubbing direction $\mathbf{R}$ was perpendicular to one of the polarizers (inset). b) Polarized UV/vis spectra revealed an absorption maximum at $558 \mathrm{~nm}$ with a maximum intensity when the incident light was parallel to the rubbing direction.
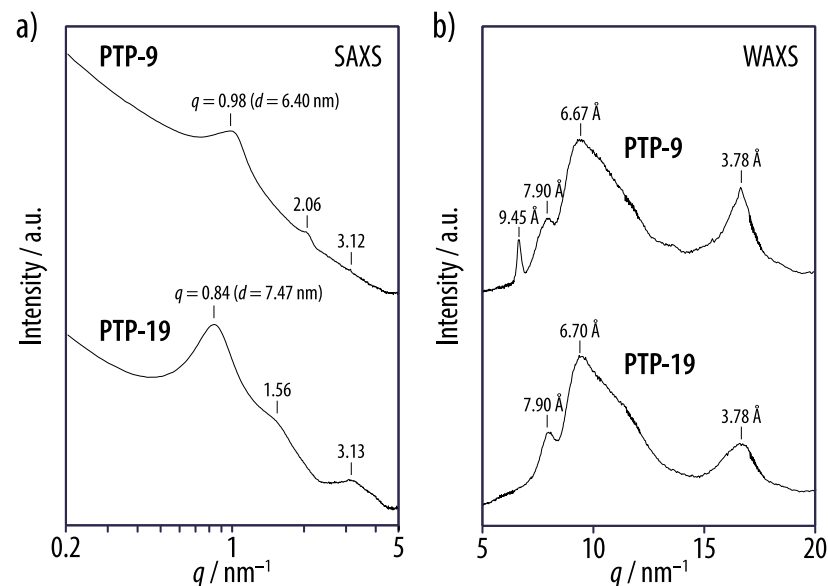

Figure 4. X-ray scattering of bulk samples of PTP-9 and PTP-19 revealed lamellar structures in the bulk. a) In the small-angle region, a reciprocal spacing ratio of $q_{1}: q_{2}: q_{3}=1: 2: 3$ and a periodicity of $6.4 \mathrm{~nm}$ for PTP-9, as well as $q_{1}: q_{2}: q_{3}: q_{4}=$ 1:2:3:4 and $7.5 \mathrm{~nm}$ for PTP-19 were observed $b$ ) In the wide-angle region, the reflection at $3.78 \AA$ was assigned to $\pi-\pi$ stacking, and additional peaks corresponding to 7.9 and $6.7 \AA$ were observed, of which the latter comprised at least the broad reflection associated with the short range order of the poly(isobutylene). The reflection at $9.45 \AA$ for PTP-9 probably originates from an impurity.
Since the larger cross-sectional areas of the poly(isobutylene)s $\left(36 \AA^{2}\right)^{29}$ as compared to the perylene bisimide $\left(28 \AA^{2}\right)^{22}$ and quaterthiophene segments $\left(21 \AA^{2}\right)^{30}$ render an interdigitation of the former unlikely, this finding implies that the different segments assume tilt angles relative to the layer normal. WAXS measurements revealed reflections at 3.8 and $7.9 \AA$, which were attributed to $\pi-\pi$ stacking and a packing distance typically observed for perylenes, respectively. A broad reflection was observed with an apparent maximum at $6.7 \AA$ that comprised the broad reflection associated with the short range order of the poly(isobutylene) at around $6 \AA . .^{31,32}$

Further investigation of the thin film nanostructure by transmission electron microscopy (TEM) confirmed the formation of lamellar phases. After doctor blading but before annealing, the thin films of both PTP-9 and PTP-19 showed stripes with a periodicity of about $7 \mathrm{~nm}$ (Figure 5a, b). Since this periodicity was in excellent agreement with the SAXS data, one can unambiguously attribute the observed stripes to lamellae oriented normal to the substrate, with the contrast in the bright-field TEM images originating from domains of the triad cores containing the sulfur atoms versus the peripheral isobutylene layers. TEM did however not allow to distinguish the central quaterthiophene block from the two perylene bisimide blocks. For PTP-19 with its longer polymer side chains, these stripes were locally aligned with a higher degree of long range order, indicative of aligned smectic lamellar phases.
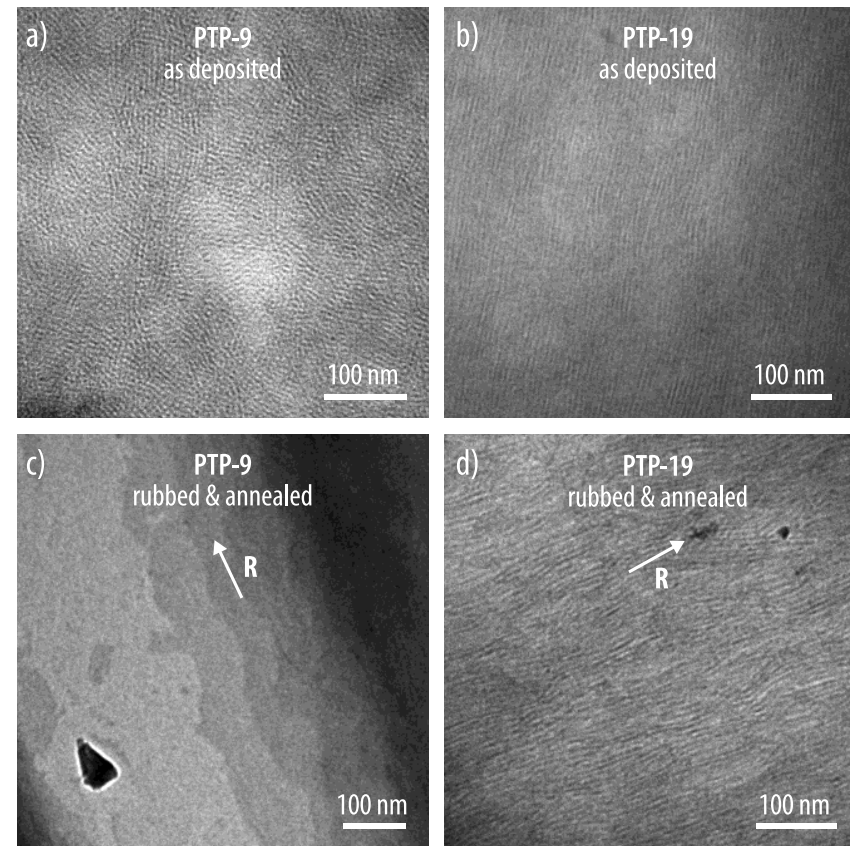

Figure 5. Transmission electron microscopy on thin film samples of PTP-9 and PTP-19 revealed stripes or terraces that were attributed to lamellae oriented edge-on or face-on relative to the substrate. a) Films of PTP-9 deposited by doctor-blading revealed stripes with a periodicity of about $7 \mathrm{~nm}$. b) doctorbladed films of PTP-19 showed a higher degree of long range order. c) Upon rubbing and annealing films of PTP-9, the lamellae changed their orientation to a face-on orientation, resulting in terraces (annealing temperature $300^{\circ} \mathrm{C}$ ). d) This reorientation did not occur for PTP-19 with longer side chains, which still showed stripes aligned by the rubbing process (annealing temperature $270^{\circ} \mathrm{C}$ ). The rubbing direction $\mathbf{R}$ is indicated by the white arrow. 

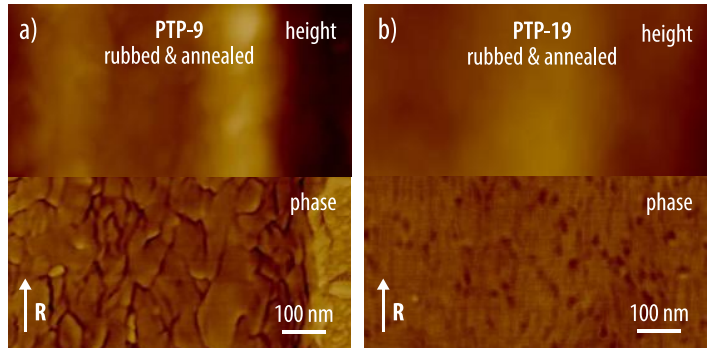

Figure 6. AFM imaging confirmed the lamellae were oriented a) face-on for PTP$\mathbf{9}$ and $b$ ) edge-on for PTP-19. Rubbing direction $\mathbf{R}$ is vertical in both cases. Color scale range are a) $140 \mathrm{~nm}$ and $90^{\circ}$, and b) $150 \mathrm{~nm}$ and $50^{\circ}$
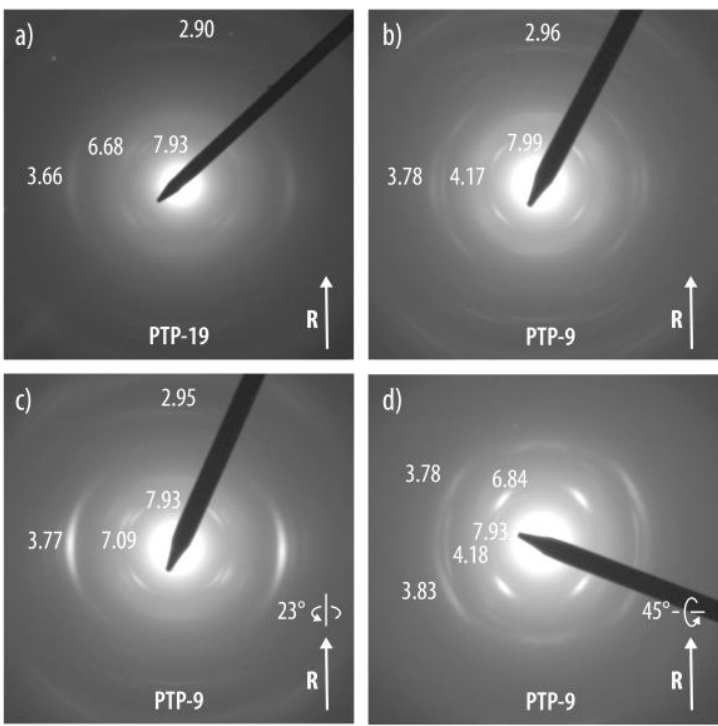

Figure 7. Electron diffraction patterns of aligned films (annealed at $300^{\circ} \mathrm{C}$ ) obtained by high-temperature rubbing. a) PTP-19 showed reflections at 7.93, 6.68 , and $3.66 \AA$ corroborating the distances observed in X-ray diffraction. This pattern is characteristic of standing lamellae. $b$ ) The diffraction pattern of PTP-9 is dominated by a set of sharp reflections characteristic of the flat-on lamellae. The most intense reflection is observed at $7.99 \AA$. c) The diffraction pattern obtained by tilting the PTP-9 sample grid by an angle of $\pm 23^{\circ}$ around the rubbing axis $\mathbf{R}$ showed the intense $3.77 \AA$ reflection corresponding to the $\pi$-stacking distance between triad molecules. d) The diffraction pattern obtained by tilting the PTP-9 sample grid by an angle of $\pm 45^{\circ}$ around the axis perpendicular to the rubbing axis $\mathbf{R}$ showed two bands at around $3.8 \AA$

After rubbing and annealing of the samples, the lamellae of PTP-19 became macroscopically aligned parallel to the rubbing direction (Figure 5d) and exhibited an azimuthal orientation distribution of about $\pm 20^{\circ}$. In the case of PTP-9, the lamellar orientation of the rubbed films changed after annealing at $300^{\circ} \mathrm{C}$, from an "edge-on" to a "face-on" orientation. The change in orientation of the lamellae is visible in the brightfield TEM images showing a characteristic terraced morphology (Figure 5c). A similar reorientation and its dependence on the molecular length had previously been observed for other perylene bisimide derivatives ${ }^{33}$ as well as simple polystyrene-polyisoprene block copolymers ${ }^{34,35}$ where it had been attributed to the viscoelastic contrast between the two domains.

Atomic force microscopy (AFM) of rubbed films confirmed the TEM observations. AFM phase images of rubbed and annealed thin films of PTP-9 exhibited terraces characteristic of flat-on lamellae, of which the step height could not be determined from the corresponding height images, probably due to the soft nature of the poly(isobutylene) segments (Figure 6a). By contrast, the phase images of PTP-19 thin films revealed a pattern of darker and lighter stripes with a periodicity of about $7 \mathrm{~nm}$, presumably originating in the phase-segregated "harder" triad cores and the "softer" polymer segments exposed to the surface in the case of vertically oriented lamellae (Figure 6b).

Electron diffraction of the aligned thin films allowed us to obtain more insight into the molecular arrangement within the layers although a clear-cut picture of the relative orientation of quaterthiophene and perylene blocks could not be obtained because of a limited set of reflections (Figure 7). All diffraction patterns appeared sharper for PTP-9 with shorter side chains, which indicated a higher level of crystalline order as compared

a)

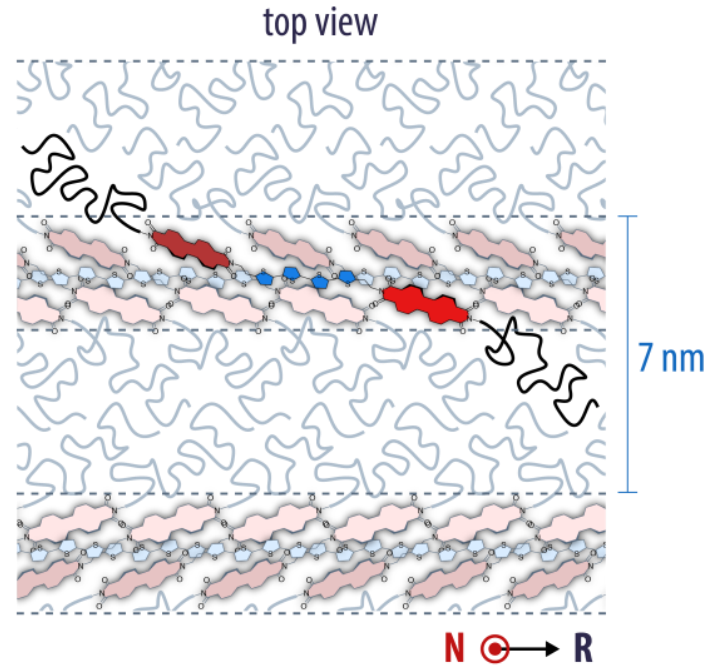

b)

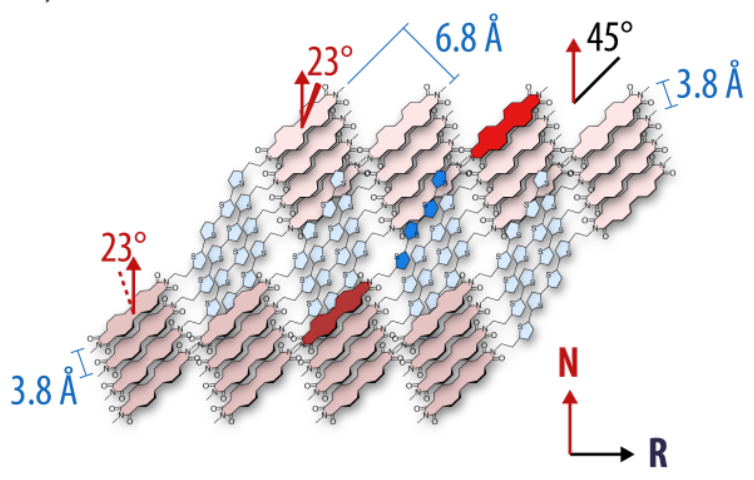

substrate

Figure 8. Schematic illustration of the molecular packing in the lamellar structure according to electron diffraction; $a$ ) in a top view of the lamellae (polymer segments not drawn to scale), b) side view of the triad in a lamella (attached polymer segments omitted for clarity); the triad cores are, on average aligned with their long axes parallel to the rubbing direction $\mathbf{R}$; according to the ED experiments with a tilting stage, they have an inclination of $45^{\circ}$ relative to the direction normal to the substrate $\mathbf{N}$, and the $\pi$-conjugated planes (supposedly, of the perylenes) have an angle of $\pm 23^{\circ}$ relative to $\mathbf{N}$ in a plane perpendicular to $R$. 
to PTP-19 thin films. In agreement with the distances obtained from XRD, PTP-19 showed reflections corresponding to distances of $d=7.93,6.68$, and $3.66 \AA$, the latter being close to the $\pi-\pi$ stacking distance observed for perylenes. PTP-19 showed always lamellae more or less normal to the substrate whatever the annealing temperature. Instead, for PTP-9, changing the annealing temperature from $200^{\circ} \mathrm{C}$ to $300^{\circ} \mathrm{C}$ resulted in a clear change of the diffraction pattern with the presence of intense reflections at $2.96 \AA$, $3.78 \AA$ and $7.99 \AA$ in films annealed at $300^{\circ} \mathrm{C}$. When tilting the sample by an angle of $\pm 23^{\circ}$ (Figure $7 \mathrm{c}$ ) around the rubbing direction $\mathbf{R}$, the diffraction pattern showed a maximum intensity of the equatorial reflection at $3.77 \AA$, which corresponds to the $\pi$ stacking period between the perylenes and/or quaterthiophene segments (as also observed by XRD, Figure 4). At the same time, tilting the sample $\pm 45^{\circ}$ around the axis perpendicular to the rubbing direction (Figure $7 \mathrm{~d}$ ) maximized the intensity of the reflections at $6.84 \AA$. One may conclude that the molecular long axis is tilted $45^{\circ}$ relative to the substrate in the rubbing direction and the $\pi$-stacking direction has a component that has a $23^{\circ}$ angle relative to the substrate (Figure 8 ). At the same time, the molecules must have a small angle $\pm \theta$ with the lamellar orientation so that their long axes are, on average oriented parallel to the latter (according to polarized optical microscopy).

\section{Charge Generation under Illumination}

The structural characterization of thin films prepared from PTP-9 and PTP-19 showed that both materials form lamellar phases that were macroscopically aligned and retained their "edge-on" orientation upon rubbing in the case of PTP-19. Since this structure would render the system interesting for charge generation and transport, we proceeded to study excitation and charge transfer processes in these materials in solution and in thin films by means of steady state and TA spectroscopy. To this end, solutions of PTP-19 in tetrachloroethane (TCE; $c=10 \mu \mathrm{mol} / \mathrm{L}$ ) thermally equilibrated at $100^{\circ} \mathrm{C}$ for $1 \mathrm{~min}$, as well as solutions of a mixture of the reference compounds 5/6 (2:1) at the same concentration of chromophores, remained molecularly disperse for several hours at room temperature, according to UV/vis spectroscopy (Figure 9). However, while the emission spectrum of the mixture at an excitation wavelength of $400 \mathrm{~nm}$ was a superposition of the spectra of the two chromophores, the emission spectrum of PTP-19 resembled the emission of the perylene bisimide alone, but with its intensity quenched by $99 \%$. The absence of any quaterthiophene emission feature in the emission spectrum of PTP-19 suggests an efficient energy transfer from the quaterthiophene to the perylene moiety, while the strong quenching of the perylene bisimide fluorescence is an indication of a subsequent charge transfer.

In order to verify this hypothesis, TA spectroscopy was performed on the triad PTP-19, the individual reference molecules 5 and 6 as well as their mixture 5/6 (2:1), both in molecularly disperse solutions in TCE and in thin films (see Supplementary Figure S3).

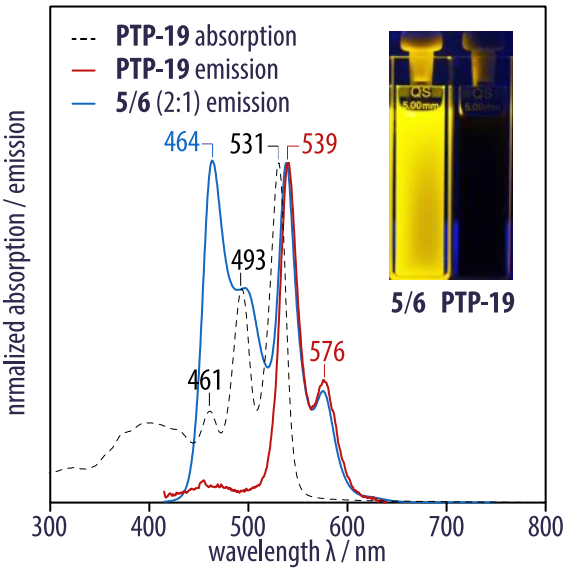

Figure 9. The emission spectrum (upon excitation at $400 \mathrm{~nm}$ ) of PTP-19 (red) was identical to the emission of the perylene $\mathbf{5}$ (not shown). However, compared to the mixture 5/6 (2:1) with the same composition of the individual chromophores (blue), fluorescence was quenched by more than $99 \%$ (inset). In comparison with the mixture, the absence of quaterthiophene emission feature in the emission of the triad PTP-19 suggested an energy transfer to the perylene moiety.

Since the absorption bands of the two chromophores in the solution-phase spectra were well separated, the perylene bisimide moieties could be exclusively excited at $530 \mathrm{~nm}$, while mostly the quaterthiophene chromophores were excited at $390 \mathrm{~nm}$. Exciting the perylene bisimide 5 or the mixture 5/6 (2:1) at $530 \mathrm{~nm}$ yielded identical TA spectra showing the ground state bleaching of the perylene bisimide, its stimulated emission, and the absorption of its $S_{1}$ excited state $(710 \mathrm{~nm})$, whose lifetime exceeded the experimentally accessible time window of 1 ns (Figure 10a and Supplementary Figure S4). Similarly, the TA spectra of the mixture 5/6 (2:1) excited at $390 \mathrm{~nm}$ were comparable to those of the pure quaterthiophene $\mathbf{6}$, as they showed the transition of the excited quaterthiophene from singlet state (absorbing around $706 \mathrm{~nm}$ ) to the triplet state (absorbing at $617 \mathrm{~nm}$ ) with a time constant of $400 \mathrm{ps}$, in addition to the TA features of the perylene bisimide 5 that also weakly absorbs at $390 \mathrm{~nm}$ (Figure 10b and Supplementary Figure S4). Thus, one can conclude that the quaterthiophene and the perylene bisimide chromophores do not exert an influence on their respective TA spectra at the employed concentration $(c=10 \mu \mathrm{mol} / \mathrm{L})$, when they are not covalently linked.

By contrast, the initially populated $S_{1}$ state of the perylene bisimide moiety was quenched within a few picoseconds in the case of the triad PTP-19 excited at $530 \mathrm{~nm}$ (Figure 10c). After an initial weak decay of the $S_{1}$ spectral features on the 0.1 ps timescale (Figure 10e), we observed a decrease of the stimulated emission that was associated with the rise of two new bands at 690 and $717 \mathrm{~nm}$, which can be attributed to the quaterthiophene radical cation and the perylene radical anion, respectively. ${ }^{36,37}$ Afterwards, the ground state bleaching of the perylene bisimide and both peaks of the charged species decreased to zero. It can be concluded that charge separation occurred by hole transfer from the $S_{1}$ state of the perylene bisimide to the quaterthiophene, followed by charge recombination. The two processes were correlated to time constants of 5 and 27 ps, respectively, as deduced from multiexponential global analysis (Figure 10e). 

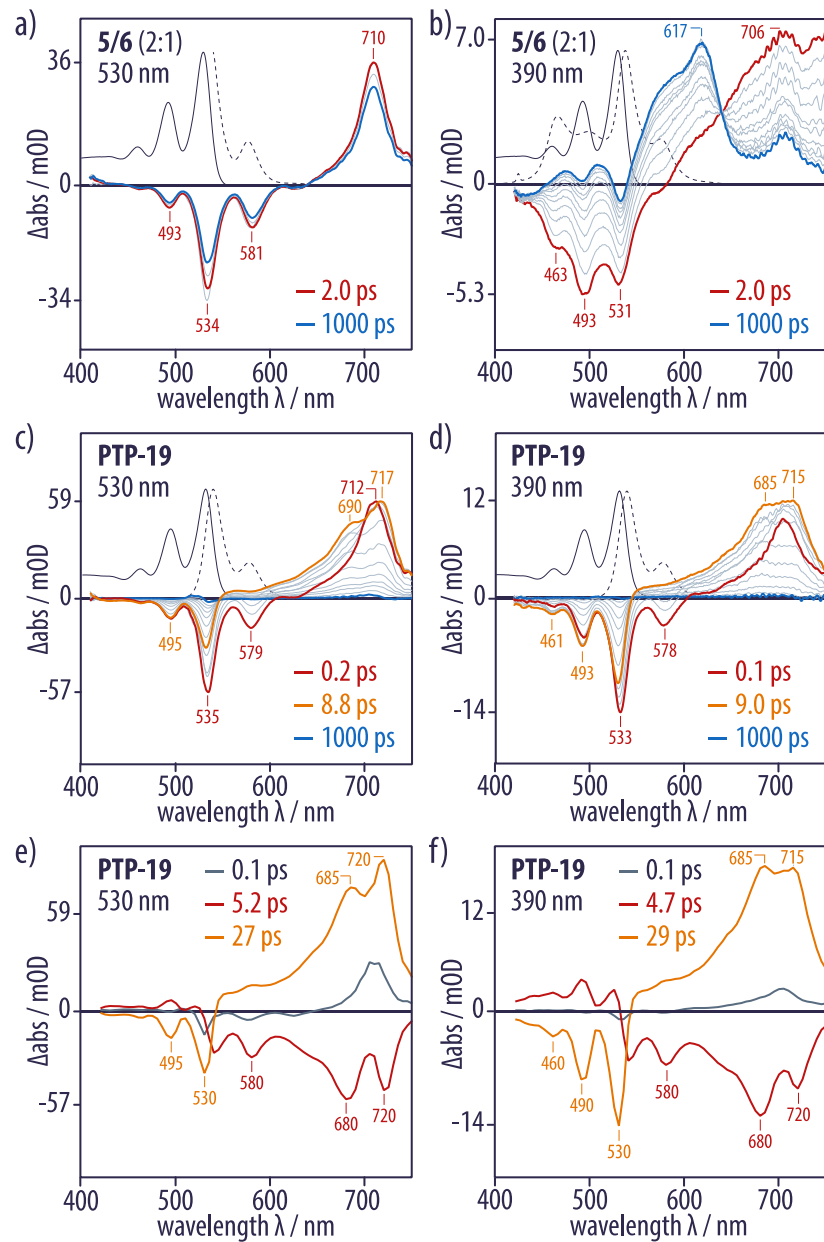

Figure 10. Transient absorption spectroscopy of the triad PTP-19 in solution revealed charge separation and recombination upon light absorption. a) TA spectra of the mixture 5/6 (2:1) excited at $530 \mathrm{~nm}$ showed the typical ground state bleaching, stimulated emission, and $\mathrm{S}_{1}$ photoinduced absorption of the perylene bisimide without any influence of the quaterthiophene 6 . b) TA spectra of 5/6 (2:1) excited at $390 \mathrm{~nm}$ showed the quaterthiophene in the $\mathrm{S}_{1}$ state, which evolved to the triplet state with a time constant of 400 ps, as well as an additional contribution from the perylene in the $S_{1}$ state since it is weakly absorbing at $390 \mathrm{~nm}$; no influence of the perylene on the excited quaterthiophene was observed. c) TA spectra of PTP-19 excited at $530 \mathrm{~nm}$ : from the perylene in the $S_{1}$ state (red), charged species formed (orange), and recombined to the ground state (blue). d) TA spectra of PTP-19 excited at $390 \mathrm{~nm}$ were almost identical to $c$ ), showing that an energy transfer from the quaterthiophene to the perylene occurred faster than the resolution of the experimental setup. e) Multi-exponential global analysis (Convolution of Gaussian IRF with three exponential functions) of PTP-19 excited at $530 \mathrm{~nm}$ correlated charge separation to a time constant of $5 \mathrm{ps}$ (red) and recombination to a time constant of 27 ps (orange). $f$ ) Multi-exponential global analysis of PTP19 excited at $390 \mathrm{~nm}$ was almost identical to e). Absorption and emission spectra of the samples are shown in solid and dashed black lines, respectively.

It should be noted that a small, long-lived photoabsorption at about $710 \mathrm{~nm}$ was observed that was tentatively attributed to small amounts of free perylene bisimide $\mathbf{5}$ as an impurity in the sample. Upon excitation at $390 \mathrm{~nm}$, the triad PTP-19 did not exhibit any feature of quaterthiophene in the singlet or triplet state (Figure 10d). The TA spectra instead only revealed the excited perylene bisimide in the $S_{1}$ state, from which charge separation and recombination occurred with similar time constants as after excitation at $530 \mathrm{~nm}$. The relative contribution of the excited perylene bisimide was now significantly larger than in the case of the mixture $\mathbf{5 / 6}$ excited at $390 \mathrm{~nm}$. Consequently, this contribution in the triad PTP-19 cannot be explained by the weak absorption of the perylene bisimide at $390 \mathrm{~nm}$ alone, and suggests an energy transfer from the excited quaterthiophene to the perylene bisimide faster than the time resolution of the experimental setup.

TA measurements were then conducted on thin film samples obtained by drop-casting 5, 6, a mixture of 5/6 (2:1), or PTP-19 from TCE solutions. As had been the case for the solutionphase samples, the TA spectra of 5 and the mixture 5/6 (2:1) were identical upon $530 \mathrm{~nm}$ excitation, suggesting selective excitation of the perylene bisimide in the mixture. These spectra showed the perylene bisimide ground state bleaching in the $420-570 \mathrm{~nm}$ region, the stimulated emission at $560 \mathrm{~nm}$, and a broad photo-induced absorption in the region above $600 \mathrm{~nm}$ (Figure 11a and Supplementary Figure S4). The decay of these three features was associated with the same time constant and was thus correlated.
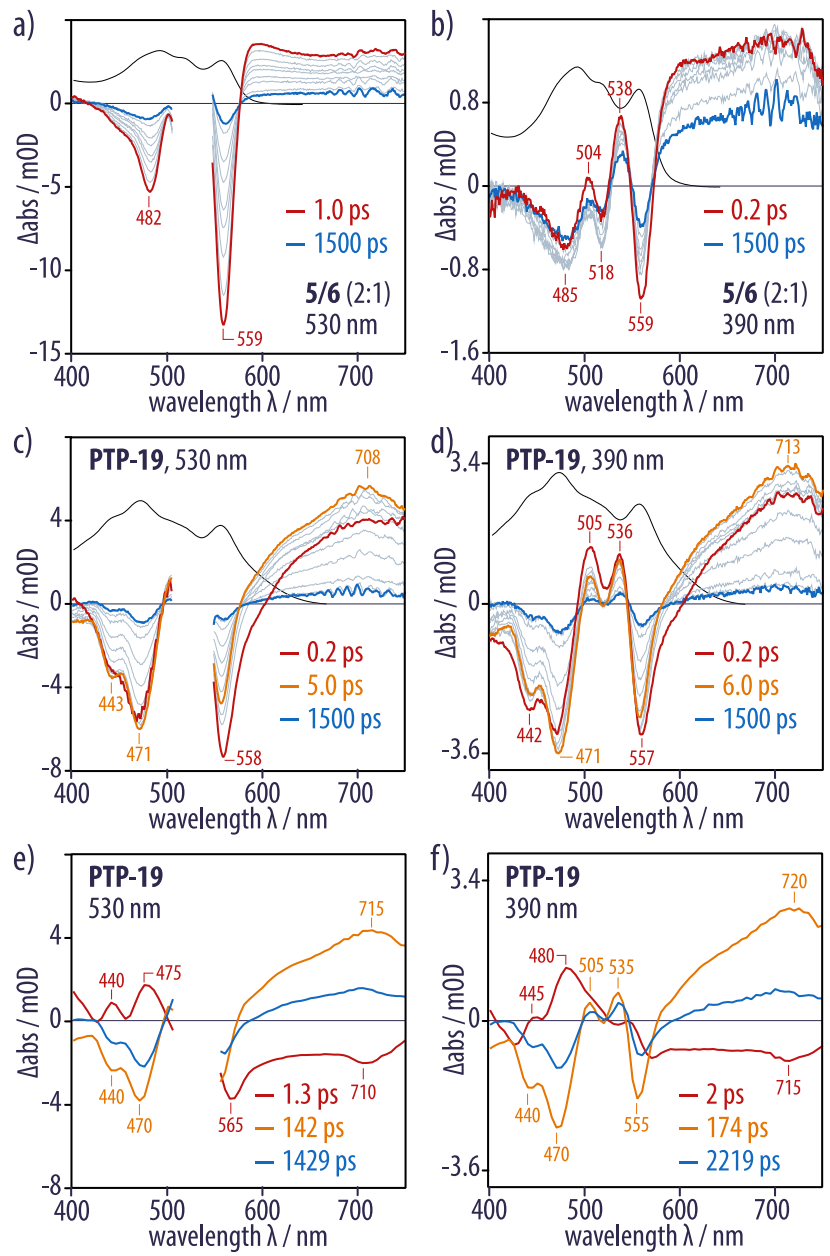

Figure 11. Transient absorption spectroscopy in thin films of PTP-19 showed a slower charge recombination than in solution and the formation of long-lived charge carriers. a) TA spectra of the mixture 5/6 (2:1) excited at $530 \mathrm{~nm}$ were similar to those of the perylene 5 alone (Supplementary Figure S4). $b$ ) TA spectra of 5/6 (2:1) excited at $390 \mathrm{~nm}$ looked like a superposition of the spectra of both pure compounds excited at the same wavelength (Supplementary Figure S4). $c, d$ ) TA spectra of PTP-19 excited at $530 \mathrm{~nm}$ and at $390 \mathrm{~nm}$ were comparable and showed the formation of charged species with a broad absorption peak at around $710 \mathrm{~nm}$. e-f) Multi-exponential global analysis of PTP-19 excited at $530 \mathrm{~nm}$ and at $390 \mathrm{~nm}$ revealed charge separation and recombination occurred with time constants of 1 and $140 \mathrm{ps}$, respectively; long-lived charge carriers were formed. Absorption spectra of the samples are shown in solid black lines. 
At an excitation wavelength of $390 \mathrm{~nm}$, the perylene bisimide chromophore was excited more significantly in addition to the quaterthiophene, as compared to the solution-phase samples, since the perylene bisimide absorption in the solid-state aggregated form is significantly extended to the blue. TA spectra of films of the mixture 5/6 (2:1) (Figure 11b) appeared like the superposition of the TA spectra of $\mathbf{5}$ and $\mathbf{6}$ excited at the same wavelength (see Supplementary Figure 54 ). The ground state bleaching, stimulated emission, and broad photoinduced absorption of the perylene were superimposed with the broad photo-induced absorption of the quaterthiophene that featured a maximum at around $700 \mathrm{~nm}$. On the other hand, the TA spectra of the triad PTP-19 excited at either 530 or $390 \mathrm{~nm}$ were very similar to one another and showed a different evolution than the reference mixture (Figure 11c,d). The initially excited state (mainly due to the aggregated perylene bisimides) was characterized by the ground state bleaching below $560 \mathrm{~nm}$, the stimulated emission at $560 \mathrm{~nm}$, and a broad photo-induced absorption with a peak at about $710 \mathrm{~nm}$. While the broad photo-induced absorption certainly had a contribution from the excited perylene-bisimide aggregates, the peak at 710 was reminiscent of the absorption of the charged species in solution and thus tentatively attributed to charged species in the solid state. The broader aspect of the charge band might be related to higher charge delocalization in the solid state. The initial increase of this charge peak was correlated to a decrease of the stimulated emission, associated with a time constant of 1-2 ps, and attributed to charge separation. It should be noted that the global analysis revealed a simultaneous increase of the ground state bleaching (peaks around 440 and $470 \mathrm{~nm}$ ) correlated to the same time constant of 1-2 ps (Figure 11e,f). A possible explanation of this phenomenon would be the migration of excitons or charges to regions where the absorption coefficient of the perylene is different due to disorder within the film, which supposedly occurred at a time constant similar to the charge separation. Finally, the decay of the ground state bleaching and the peak at $710 \mathrm{~nm}$ was attributed to charge recombination occurring with a time constant of about 150 ps according to the global analysis. Differently from the solutionphase spectra, however, the system did not completely return to the ground state. Instead, a broad absorption peak at $710 \mathrm{~nm}$ persisted on the experiment time scale of $1.5 \mathrm{~ns}$, suggesting the formation of long-lived charge carriers in the thin film samples.

The TA spectra of thin film samples of PTP-9 were qualitatively identical to those of PTP-19. A detailed comparison of the time evolution of the TA intensity at $710 \mathrm{~nm}$, however, showed that the charge-separated species were slightly more long-lived for PTP-19 than for PTP-9 (Figure 12a). While the difference was small, it may still indicate that the higher degree of nanostructural order of PTP-19 was beneficial for charge delocalization and stabilization. Furthermore, the anisotropy of the charged species at $710 \mathrm{~nm}$ was evaluated on films of PTP-9 that had been excited at $530 \mathrm{~nm}$ (Figure 12b). As expected, films before alignment by rubbing showed an anisotropy coefficient lower than 0.4 , while aligned films had a

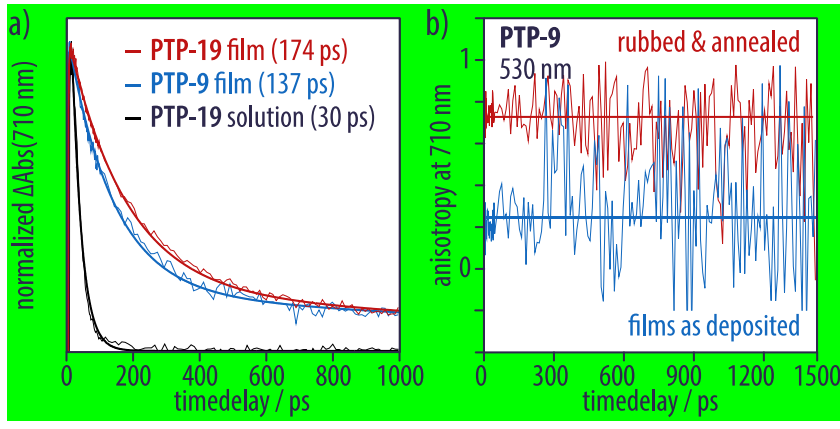

Figure 12. a) Comparison of the TA dynamics at $710 \mathrm{~nm}$ and the corresponding fit after excitation at $530 \mathrm{~nm}$; recombination was much slower in films compared to solutions, and films made from PTP-19 showed a slower recombination as compared to PTP-9. b) Anisotropy calculated for PTP-9 at $710 \mathrm{~nm}$ after excitation at $530 \mathrm{~nm}$; aligned films showed an anisotropy well above that of non-aligned films; the stability of the anisotropy for non-aligned films suggested that charges did not travel between domains within the $1.5 \mathrm{~ns}$ timeframe of the experiment.

coefficient well above. For the non-aligned film, the anisotropy was stable over the timescale of the experiment, which indicated that the charged species did not travel across domain boundaries and kept their (local) alignment.

In summary, TA spectroscopy confirmed that charge separation occurred in the triads PTP-9 and PTP-19 upon light absorption. The initial charge separation process involved the excited state of the perylene bisimide moiety, which could be accessed either by direct excitation or by energy transfer from the excited quaterthiophene moiety. Charge generation was found to be faster and charge recombination slower in thin films as compared to solution-phase samples. The faster charge separation was presumably due to the closer proximity of the chromophores in the solid state, while the slower recombination and especially the formation of long lived charged species was most likely due to the higher stability of charges delocalized within the respective sublayers of the triad lamellae.

\section{Conclusions}

We prepared a perylene-quaterthiophene-perylene triad substituted with poly(isobutylene) segments that served to induce the reliable formation of lamellar phases by means of the phase segregation between the rod-like triad core and the attached random coil polymers. In thin films, the triads indeed gave rise to lamellar structures that could then be aligned by rubbing and annealing. The longer side chains of the derivative PTP-19 helped to increase the long-range nanoscale order and maintain an "edge-on" orientation of the lamellae relative to the substrate after rubbing and annealing. In solution, the fluorescence of the triad PTP-19 was quenched to more than 99\% compared to the mixture 5/6 (2:1) of the same composition of the chromophores. Transient absorption measurements confirmed that fluorescence quenching was due to charge separation between the perylene and quaterthiophene moieties, followed by recombination. In thin films, this recombination was slower, and long-lived charged species were observed, presumably due to stabilization through delocalization of the separated charges within the 
respective sublayers of the triad lamellae. The stable anisotropy factor recorded for nonaligned films suggested that charges did not travel across domain boundaries within the $1.5 \mathrm{~ns}$ of the experiment. In this way, the higher degree of long-range order in films of PTP-19 should enhance charge stabilization, and was likely responsible for the even slower charge recombination compared to films of PTP-9. An investigation of photovoltaic devices from these materials was beyond the scope of the present study, in particular, because it would have required using a more promising donor segment than the quaterthiophene. Nevertheless, our investigations demonstrate that the terminal attachment of soft polymer segments to a triad system represents a viable concept to prepare triad-based materials with a phase morphology suited for an ordered heterojunction, and that this morphology was beneficial for the stabilization of charge carriers.

\section{Acknowledgements}

The authors would like to acknowledge funding from the Swiss National Science Foundation (SNF Grants 200020_121812, 200020_144417, and PPOOP2_15053), the European Research Council (ERC Starting Grant 239831), the Velux Foundation (Velux Projekt 715) as well as financial support from EU interreg Rhin Solar project (C25).

\section{References}

1 N. Armaroli and V. Balzani, Angew. Chem. Int. Ed., 2007, 46, 52-66.

2 O. Morton, Nature, 2006, 443, 19-22.

3 F. Gao and O. Inganas, Phys. Chem. Chem. Phys., 2014, 16, 20291-20304.

4 J.-L. Brédas, J. E. Norton, J. Cornil and V. Coropceanu, Acc. Chem. Res., 2009, 42, 1691-1699.

5 T. M. Clarke and J. R. Durrant, Chem. Rev., 2010, 110, 67366767.

6 M. T. Dang, L. Hirsch, G. Wantz and J. D. Wuest, Chem. Rev., 2013, 113, 3734-3765.

7 M. C. Scharber and N. S. Sariciftci, Prog. Polym. Sci., 2013, 38, 1929-1940.

8 A. J. Heeger, Adv. Mater., 2013, 26, 10-28.

9 B. C. Thompson and J. M. J. Fréchet, Angew. Chem. Int. Ed., 2008, 47, 58-77.

10 P. Westacott, J. R. Tumbleston, S. Shoaee, S. Fearn, J. H. Bannock, J. B. Gilchrist, S. Heutz, J. deMello, M. Heeney, H. Ade, J. Durrant, D. S. McPhail and N. Stingelin, Energy Environ. Sci., 2013, 6, 2756.

11 S. Sweetnam, K. R. Graham, G. O. Ngongang Ndjawa, T. Heumüller, J. A. Bartelt, T. M. Burke, W. Li, W. You, A. Amassian and M. D. McGehee, J. Am. Chem. Soc., 2014, 136, 14078-14088.

12 C. Groves, Energy Environ. Sci., 2013, 6, 1546.

13 A. A. Paraecattil and N. Banerji, J. Am. Chem. Soc., 2014, 136, 1472-1482.

14 B. Gholamkhass and S. Holdcroft, Chem. Mater., 2010, 22, 5371-5376.

15 A. Yassar, L. Miozzo, R. Gironda and G. Horowitz, Prog. Polym. Sci., 2013, 38, 791-844.
16 J. Roncali, Adv. Energy Mater., 2011, 1, 147-160.

17 L. Dong, W. Li and W.-S. Li, Nanoscale, 2011, 3, 3447.

18 G. Fernández, L. Sánchez, D. Veldman, M. M. Wienk, C. Atienza, D. M. Guldi, R. A. J. Janssen and N. Martin, J. Org. Chem., 2008, 73, 3189-3196.

19 T. Nishizawa, K. Tajima and K. Hashimoto, J. Mater. Chem., 2007, 17, 2440.

20 L. Bu, X. Guo, B. Yu, Y. Fu, Y. Qu, Z. Xie, D. Yan, Y. Geng and F. Wang, Polymer, 2011, 52, 4253-4260.

21 L. Bu, X. Guo, B. Yu, Y. Qu, Z. Xie, D. Yan, Y. Geng and F. Wang, J. Am. Chem. Soc., 2009, 131, 13242-13243.

22 P.-O. Schwartz, L. Biniek, E. Zaborova, B. Heinrich, M. Brinkmann, N. Leclerc and S. Méry, J. Am. Chem. Soc., 2014, 136, 5981-5992.

23 J. Qu, B. Gao, H. Tian, X. Zhang, Y. Wang, Z. Xie, H. Wang, Y. Geng and F. Wang, J. Mater. Chem. A, 2014, 41, 1086-1097.

24 J. Kelber, H. Bock, O. Thiebaut, E. Grelet and H. Langhals, Eur. J. Org. Chem., 2011, 707-712.

25 C. Xue, R. Sun, R. Annab, D. Abadi and S. Jin, Tetrahedron Lett., 2009, 50, 853-856.

26 J. Gebers, D. Rolland, R. Marty, S. Suàrez, L. Cervini, R. Scopelliti, J. C. Brauer and H. Frauenrath, Chem. Eur. J., 2015, 21, 1542-1553.

27 R. Marty, R. Nigon, D. Leite and H. Frauenrath, J. Am. Chem. Soc., 2014, 136, 3919-3927.

28 J. Mizuguchi and K. Tojo, J. Phys. Chem. B, 2002, 106, 767772.

29 T. Tanaka, Y. Chatani and H. Tadokoro, J. Polym. Sci. Polym. Phys. Ed., 1974, 12, 515-531.

30 J. Gebers, L. Hartmann, B. Ozen, M. Schaer, S. Suàrez, P. Bugnon, R. Scopelliti, H.-G. Steinrück, O. Konovalov, A. Magerl, M. Brinkmann, R. Petraglia, P. de Silva, C. Corminboeuf and $\mathrm{H}$. Frauenrath, In preparation.

31 E. Croisier, S. Liang, T. Schweizer, S. Balog, M. M. cacute, R. Snellings, J. E. L. Cugnoni, V. E. R. Michaud and H. Frauenrath, Nature Commun., 2014, 5, 1-10.

32 R. Marty, R. Szilluweit, A. Sánchez-Ferrer, S. Bolisetty, J. Adamcik, R. Mezzenga, E.-C. Spitzner, M. Feifer, S. N. Steinmann, C. Corminboeuf and H. Frauenrath, ACS Nano, 2013, 7, 8498-8508.

33 L. Biniek, P.-O. Schwartz, E. Zaborova, B. Heinrich, N. Leclerc S. Méry and M. Brinkmann, J. Mater. Chem. C, 2015, 3, 33423349.

34 K. I. Winey, S. S. Patel, R. G. Larson and H. Watanabe, Macromolecules, 1993, 26, 2542-2549.

35 K. I. Winey, S. S. Patel, R. G. Larson and H. Watanabe, Macromolecules, 1993, 26, 4373-4375.

36 D. Fichou, G. Horowitz, B. Xu and F. Garnier, Synth. Met., 1990, 39, 243-259.

37 T. Roland, J. Léonard, G. Hernandez Ramirez, S. Méry, O. Yurchenko, S. Ludwigs and S. Haacke, Phys. Chem. Chem. Phys., 2011, 14, 273. 


\section{Table of Content Figure}

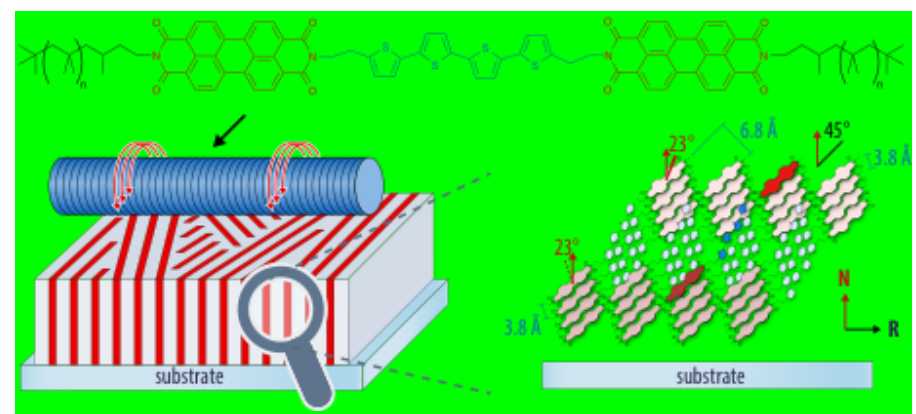

Attaching flexible polymer segments to a donor-acceptor-donor triad results in edge-on lamellae oriented that were aligned by mechanical rubbing and were investigated for their charge separation and recombination characteristics. 